\title{
Women's Experiences of Infection With Human Papillomavirus in the Face of Disease Symptoms: A Qualitative Study
}

\author{
Masoumeh Pourmohsen ${ }^{1,2}{ }^{(}$, Masoumeh Simbar $^{3,1^{*}}{ }^{\mathbb{D}}$, Fatemeh Nahidi $^{(\mathbb{D}}$, Fereshteh Fakor $^{\mathbf{C}^{(}}$, \\ Hamid Alavi Majd ${ }^{(\mathbb{D}}$
}

\begin{abstract}
Objectives: Human papillomavirus (HPV) is known as one of the sexually transmitted diseases and the main cause of cervical cancer with its own significant psychological problems. Considering the hidden social aspects associated with these behaviors and since no qualitative research has focused on this issue in Iran, the present study sought to explain women's experiences of infection with HPV. Materials and Methods: This qualitative research was conducted based on conventional content analysis. To this end, in-depth and semi-structured interviews were fulfilled with 20 individuals (13 women with HPV and 7 key informants) after obtaining participants' consent. Data analysis was also carried out simultaneously with data collection.

Results: Following the code extraction, participants' experiences in the face of HPV symptoms were grouped into two main categories of psychological responses (i.e., concern, fear and panic, unbelievable acceptance, unpleasant feelings, individual's response to the disease, as well as reactions by people, family, and husband in the face of the disease) and physical experiences of the disease (i.e., clinical symptoms and long incubation period of the virus). Each subcategory also contained a code that was demonstrated with statements provided by study participants.

Conclusions: The results of this study highlighted the importance of understanding the risk of HPV. It was further recommended to provide preventive counseling in community health centers, as well as advising and guiding patients in therapy clinics.

Keywords: Human papillomavirus, Symptoms, Qualitative study
\end{abstract}

\section{Introduction}

Human papillomavirus (HPV) is considered as one of the most commonly diagnosed sexually transmitted diseases in many countries, as well as a health concern in the present age (1). Moreover, the prevalence rate of this disease is seriously increasing (2). The HPV was reported in $7.4 \%$ of normal cervical Pap-smear test results in Iran (3). More than 100 types of HPV were further identified, and approximately 40 of these cases were recognized as the ones that cause sexually transmitted diseases (4). These viruses infect the skin and the mucous epithelial tissues of different anatomical regions (5).

Additionally, clinical manifestations of HPV infection include cutaneous warts, genital lesions and sores, laryngeal papillomatosis (recurrent respiratory papillomatosis), precancerous lesions, as well as cervical, anal, vulval, and vaginal cancers (6). However, the bulk of HPV infections are asymptomatic (7). Therefore, one cannot rely on clinical manifestations or Pap-smear test results. The sexual transmission is regarded as the most common mode of genital HPV transmission and it is mainly transferred through heterosexual intercourse. Transmission through fingers, tampons on the vulva and the vagina, as well as the transfer from mother to the fetus (vertical transmission) can also cause adolescent respiratory papillomatosis (8). The relationship between HPV and cervical cancer is proven as well (9). With regard to the potential for malignancy, the HPV is classified into two high- (carcinogenic) and low-risk (non-carcinogenic) groups (10). Furthermore, numerous cases of genital warts are developed about 6-12 months after initial infection with low-risk HPV (types 6 and 11) and spontaneous regressions have been reported in some cases $(4,11-13)$. Types 16 and $18 \mathrm{HPV}$ are also responsible for $90 \%$ of cases of cervical cancer in women, as well as $70 \%$ of vaginal and vulvar cancers and $90 \%$ of cases of anal cancer in the United States (14) which are more likely to progress to cervical cancer (15). Besides, the HPV has no definitive treatment and its treatment is only limited to removing the skin and mucosal lesions although the risk of cervical 
cancer can be reduced by prevention methods (16).

The consequences of infection with HPV are significant. The HPV infection is also associated with significant mental and psychological problems including stigmas caused by the disease (17). The positive results of HPV testing are more likely to bring about mental anxiety compared to the effects of abnormal Pap-smear test results (18). For example, in a research study, women with HPV experienced negative emotions such as shame and stigma, along with their physical experiences (19). Feeling guilty and regretful was also widespread, and women believed that HPV transmission through sexual intercourse would be blamed by peers or sex partners (20). Likewise, patients with HPV could go through psychosocial problems due to the fear of physical injury, side effects, and prognosis (21). Considering the hidden social aspects associated with these behaviors and given the fact that a qualitative study was capable of discovering the related sociocultural factors, there was a need to conduct such an investigation in this domain. Given that no qualitative study has so far evaluated the above-mentioned issue in Iran, the present study aimed to explain women's experiences of HPV infection in the face of disease symptoms.

\section{Materials and Methods \\ Study Design}

This qualitative study was fulfilled based on conventional content analysis. For this purpose, the researchers explained HPV women's experiences of dealing with the disease symptoms using in-depth and semi-structured interviews.

The study participants included HPV women living in Rasht, northern Iran, who were selected through the convenience sampling method from June to November 2017. The HPV diagnosis was also based on the symptoms of genital warts or via the polymerase chain reaction technique. The total number of the participants in the study was 20 including 13 women with HPV and 7 key informants (i.e., reproductive health specialists, gynecologists, dermatologists, urogenital tract specialists, social medicine specialists, and midwives). Then, the interviews were conducted with participants and some key informants in a private clinic. It should be noted that interviews with some other key people were performed at their private offices. Furthermore, the sample variance was observed in terms of underlying factors such as age, the level of education, occupation, marital status, the place of residence (urban or suburban areas), as well as the variation of HPV types and its complications (genital warts or cervical intraepithelial neoplasia.

The inclusion criteria for the recruitment of women with HPV in this study were all Iranian women aged between 15 and 55 years suffering from HPV, living as residents in Rasht or its suburban areas, along with having reading and writing literacy. They were also able to speak Persian and/or Gilaki. Oral and written consent for participation was further obtained as well. According to the objectives of the study, the sampling was started purposefully and continued until data saturation and the emergence of no new codes (22). To conduct the study, the first author visited gynecology clinics affiliated to Guilan University of Medical Sciences to become familiar with the patients. Before each interview, the researcher introduced herself and explained the subject and the objectives of the study. She also informed them of voluntary participation and the confidentiality of information, as well as the possibility of withdrawal from the study at any time upon their desire. Besides, she provided the required oral explanations to the participants and obtained their consent to do the interviews and to fulfill the recording process.

\section{Data Collection}

For data collection, demographic characteristics such as age, the level of education, and marital status were recorded and interviews were conducted based on the questionnaire guide. The given guide was also administered as a pilot study on a few women with HPV before using the qualitative section, followed by resolving its defects and ambiguities. Face-to-face interviews were started with a general question (i.e., Talk about your experiences in the face of disease symptoms) and continued with open-ended ones. To get more information and to fit the responses, indepth questions (e.g., Can you explain more about this? and Can you give an example of this experience that happened to you to make it better understood?). Each interview lasted between 45 and 60 minutes. Moreover, all interviews were further recorded and the participants were ensured that the audio files would be kept confidential and safe. At the end of the interviews, the participants were asked to speak more if they desired, and then they were asked about the time of the next interview. After completing the interviews, the recordings were transcribed following several hours of listening by the researcher. Finally, the non-verbal features of the interviewees (speech and facial expressions) were taken into account.

\section{Data Management and Analysis}

Validity and acceptability, transferability and appropriateness, variability and reliability, as well as assurance and stability were used to verify the findings of the study (23). The researcher increased the credibility of the findings by assigning sufficient time to data collection and studying them repeatedly. Additionally, the credibility of the data was increased by combining data collection methods (i.e., individual interviews, observations, and field notes), location integration (two women's clinics in the city), and diversity in the characteristics of the participants (people with different age, levels of education, marital status, occupation, as well as the diversity of HPV types and its complications), and the variety of key informants. To verify the extracted content, a number of interviews were coded and then returned to the participants to 
determine the extent to which the research objectives were reviewed by contributing members. To confirm the appropriateness, the researcher tried not to interfere with their assumptions as far as possible during data collection and analysis. In addition, the codes and categories were reviewed by research team assistants and an agreement was made between the given codes, and ultimately, the correctness of the coding process was reviewed, followed by providing several suggestions in the subsequent interviews. Further, the reliability of the findings was determined by the reviews conducted by partners outside the research team (reproductive health and gynecology specialists). After transcribing the recorded interviews, the colleagues outside the research team listened to the recordings and proposed the necessary changes. For the purpose of data transferability, the researcher presented the findings of the study to several women with HPV that were not present in the study for further reviews. Similarly, there were attempts to provide a complete description of the context and the culture available, sample selection, participants' characteristics, data collection and analysis methods, along with the examples from participants' statements.

The data from the interviews were analyzed via conventional content analysis using Graneheim and Lundman's approach (24). The MAXQDA 10 software (VERBI, Germany) was also used to manage data. Furthermore, data analysis began from the time of the first interview simultaneously with the interviews (simultaneous analysis) so that the researcher transcribed the information as soon as possible after interviewing and listening to the recordings. The transcribed information was reviewed and matched once again with the recordings in order to increase the accuracy of the data. Then, the basic concepts in each text were identified and each primary concept was compacted in the code and converted accordingly. Next, the same code was used in a subcategory. In the present study, the subcategories were grouped into one category based on their common characteristics.

\section{Results}

The findings of this part of the study continued by providing the participants' demographic characteristics information (Table 1), and then by a general overview of participants' experiences, as well as categories and subcategories extracted from the interviews (Table 2). It should be noted that the participants' experiences in the face of HPV symptoms emerged in two categories, eight subcategories, and 28 codes.

\section{Psychological Responses}

This category was comprised of the subcategories of concern, fear, and panic, unbelievable acceptance, unpleasant feelings, an individual's response to the disease, as well as reactions by people, family, and husband in the face of the disease symptoms. The experiences in the majority of the participants showed that the psychological responses of the disease were very annoying and this was the reason for not referring to healthcare centers to treat the disease in most cases.

\section{Concern}

The transmission of the disease to the fetus was the main concern raised by most participants in this study and it was also the cause for continuing the therapy. In this regard, one of the participants mentioned that: "I am really worried about my baby. Now, I have to ask the doctor if there is a way not to transfer the disease to my baby or not?" (31 years old, married, associates degree).

Moreover, worrying about being sick was the cause of disappointment in the majority of study participants which led them to ignore tracking down the disease. In this case, one of the participants stated that: "I am so concerned about not to be treated and I think there may be no treatment at all. Now, no matter what doctor I refer to, nothing can be done when there is no treatment. What a doctor can do for me? It is not guaranteed to be fine. If you ask me, this is another problem." (29 years old, married, diploma).

\section{Fear and Panic}

The vast majority of the participants were afraid of cancer and death. There was also a fear of recurrence and the aggravation of the disease. Some study participants also described such fear and panic as the reasons for preventing cancer. In this regard, one of the participants believed that:

"If the disease keeps going, it will lead to cancer. If it is not treated, the virus can quickly lead to cervical cancer. I am scared of going and seeing a doctor and showing sensitivity in this regard" (22 years old, single, bachelor's degree).

The recurrence and worsening of the disease were the

Table 1. Participants' Demographic Characteristics of $(\mathrm{N}=20)$

\begin{tabular}{llc}
\hline $\begin{array}{l}\text { Demographic } \\
\text { Characteristics }\end{array}$ & $20-25$ & $\begin{array}{c}\text { Number } \\
\text { (individuals) }\end{array}$ \\
\hline \multirow{2}{*}{ Age } & $26-30$ & 6 \\
& $31-35$ & 2 \\
& $36-40$ & 4 \\
Level of education & Over 40 & 1 \\
& Under diploma & 7 \\
& Diploma & 3 \\
& Associate degree & 3 \\
& Bachelor's degree & 2 \\
& Ph.D. & 6 \\
Marital status & Single & 3 \\
& Married & 16 \\
& Divorced & 1 \\
Occupation & Housewife & 7 \\
& Employed & 13 \\
\hline \multirow{3}{*}{. } & &
\end{tabular}


Table 2. Categories and Subcategories of Women's Experiences With HPV in the Face of Disease Symptoms

\begin{tabular}{|c|c|c|}
\hline Categories & Subcategories & Guiding Codes \\
\hline \multirow{6}{*}{$\begin{array}{l}\text { Psychological } \\
\text { reactions to the } \\
\text { disease }\end{array}$} & Concerns & $\begin{array}{l}\text { - Concerns about transferring the virus to the fetus } \\
\text { - Concerns about the incurability of the disease }\end{array}$ \\
\hline & Fear and panic & $\begin{array}{l}\text { - Fear of cervical cancer and death } \\
\text { - Fear of recurrence or worsening of the disease }\end{array}$ \\
\hline & Unbelievable acceptance & $\begin{array}{l}\text { - One's own or spouse's misfortunate HPV infection } \\
\text { - Belief in bad luck }\end{array}$ \\
\hline & Unpleasant feelings & $\begin{array}{l}\text { - Stress caused by the disease } \\
\text { - Depression and emotional failure } \\
\text { - Being nervous } \\
\text { - Feeling uncontrollable in life } \\
\text { - Shame and embarrassment } \\
\text { - Feeling guilty and regretful }\end{array}$ \\
\hline & Individual's response to the disease & $\begin{array}{l}\text { - Marital violence and conflict } \\
\text { - Tendency to get separated } \\
\text { - Concealment of the disease } \\
\text { - Not taking the disease seriously }\end{array}$ \\
\hline & $\begin{array}{l}\text { Reactions by people, family, and husbands in the } \\
\text { face of the disease }\end{array}$ & $\begin{array}{l}\text { - Husband's concealment } \\
\text { - Husband's disapproval } \\
\text { - Husband's disregard } \\
\text { - Loyalty and acceptance } \\
\text { - Misbehaviors and family interference } \\
\text { - Taboos in the community }\end{array}$ \\
\hline \multirow[t]{2}{*}{$\begin{array}{l}\text { Physical experiences } \\
\text { of the disease }\end{array}$} & Clinical symptoms & $\begin{array}{l}\text { - Genital warts } \\
\text { - Itching and burning } \\
\text { - Vaginal discharge and infection } \\
\text { - Recurrence and exacerbation of symptoms }\end{array}$ \\
\hline & Long incubation period of the virus & $\begin{array}{l}\text { - No infection in the husband } \\
\text { - No exposure to symptoms }\end{array}$ \\
\hline
\end{tabular}

Note. HPV: Human papillomavirus.

cause of fear and panic in most participants. In this respect, a participant indicated that: "I am feeling frightened. Fear has always been within me and it is impossible to get out of this situation" (31 years old, married, diploma).

Unbelievable Acceptance

A large number of the participants were complaining about themselves or their husbands for being infected with HPV and believed that they were affected due to misfortune. Such complaints and beliefs in bad luck were regarded as factors for disease acceptance and the obstacles for its prevention. In this regard, one participant added that: "Why should I get genital warts? Why should my husband get genital warts? We were very fortunate enough and we had a lot of money. What a misfortune?" (31 years old, married, diploma).

\section{Unpleasant Feelings}

Some participants experienced depression and emotional failure due to discontinuing treatment and prevention. For example, one of the participants stated that:

"I got depressed when I found out I was affected by this disease. I became so sad when I realized that I was infected with this disease. I felt it like an emotional blow" (22 years old married, bachelor's degree).
In addition, nervousness was one of the common feelings among many participants that persuaded them to prevent the decision to follow treatments. The same participant mentioned that: "I feel sad. A person is not normal at this time. It was a time full of nervousness, it was really terrible. I was very nervous."

The shame and embarrassment of sexual arousal was the feeling that most participants experienced and avoided visiting the doctor for treatment. In this respect, a 31-yearold married participant believed that: "What should I say? One is embarrassed to go and visit the doctor. What should I talk about with the doctor, and how and when I got the disease."

There was also a feeling of being guilty and regretful for the possibility of the unnecessary transmission of the disease to others in most participants. The same participant added that: "How many people have already been infected? This is kind of suffering for people."

Individual's Response to the Disease

This subcategory consisted of spousal conflicts and even a tendency to get separated, individual secrecy, and serious illness. Many participants believed that a transfer from their husband the cause of the disease, which was the reason why they had discords and behaved violently. This 
dispute was an obstacle to the pursuit of the disease and its prevention. In this respect, one of the participants stated that: "My husband and I got into trouble with each other. We had conflicts, too. I said that it was not my right to be infected with the disease. It led to another fight. I said that he did not value me because he hurt me with this infection" (31 years old, married, bachelor's degree).

Another participant insisted on separating from his husband and stated that: "I want to get divorced. There is no other resort. Why should he treat me like this?" (23 years old, married, diploma). Two weeks later, the researcher called this participant for the next interview. This infected woman indicated that she was applying for a divorce and now she was living in her mother's house while no longer living with her husband (a reminder of the researcher).

A large number of participants disclosed no HPV infection from their husbands because they were worried about how their spouse thought about them. This concealment was a barrier to prevent disease complications. For example, a participant reiterated that: "I did not talk about this issue. I did not know what my husband would think about me. He might assume I was having a relationship with someone else." (22 years old, married, under diploma).

At the same time, a number of participants did not take the virus seriously and did not seek for treatments. Accordingly, a single 31-year-old participant stated that: "I did not take the disease seriously. You know people do not take it seriously, so take it easy! Many people have worries in this regard."

Reactions by People, Family, and Husbands

A range of taboos regarding the disease in the community, negative attitudes, and family interference was identified as barriers to disease prevention by many participants.

In this respect, the taboo of the disease in the community was reported as one of the important reasons for no prevention and treatment by the study participants. For example, a 31-year-old married participant mentioned that: "People think it is contagious like hepatitis. They treat me in a special way that I have HIV/AIDS or hepatitis. People do not get close to you and they do not understand that you are sick."

Many participants complained about misbehaviors by individuals around them, and they considered it as a reason to hide the disease. In this respect, one of the participants stated that: "My sisters treated me badly. I asked them what to do? I tried not to touch their items. My mom found about the disease and told me to get divorced. My mother-in-law also said that I had been already sick" (31 years old, married, associate degree).

Most participants complained about secrecy, disapproval, and neglect of their spouse or sex partner and mentioned these issues as the barriers to HPV prevention. A married 31-year-old participant added that "My husband did not tell me that she had a girlfriend. All things considered, he told me he had no relationship with anyone. I was not with anyone else. He hid everything from me all the time?"

Regarding her husband's disapproval, the same participant continued that "I told my husband that the doctor said I might have taken warts from my spouse. My husband said that you did not observe it. What was up to him?"

Spousal disregard was also one of the reasons mentioned by most participants for not caring about the disease. Accounting for her husband's disregard, a participant mentioned that "When I was hospitalized for two days and went into the operating room, my husband did not come to visit me even once. It did not matter at all." (32 years old, married, bachelor's degree).

However, two participants were pleased with their husband's loyalty and acceptance, suggesting it as an encouragement for continued treatment. In this regard, a participant added that "I told my husband that I got warts and the doctor told me I had a cancer risk. My husband admitted it easily. He asked about what we had to do to treat it? I told him the necessary actions we needed to do" (25 years old, married, under diploma).

\section{Physical Experiences}

This category consisted of two subcategories of clinical symptoms and a long incubation period of the virus. Most participants considered clinical symptoms such as warts, burning and itching, vaginal discharge, and symptom recurrence as factors facilitating the prevention of disease because these symptoms forced them to refer to healthcare centers. However, the latent period of the virus was thought to be due to delays in diagnosis and treatment.

\section{Clinical Symptoms}

Itching, burning, and vaginal infection were among the symptoms that prompted people to visit the doctor quickly. Most participants referred to healthcare centers as they observed warts. In this respect, a 22 -year-old single participant declared that "First warts I observed were small but they had fast growth. They grew very fast. First, they were not very big. I had a lot of vaginal infections and discharge. I had to go and visit the doctor very soon. I had a lot of itching and burning."

The recurrence of the symptoms was also underscored by most participants as a facilitator for preventive interventions. Accordingly, a 32-year-old married woman indicated that "Every year, the disease recurs. I was infected with this disease since I got married. A few years ago when my illness recurred once or twice, I went to the doctor and she burned my warts".

\section{Long Incubation Period of the Virus}

This subcategory included the absence of the virus in one's spouse or sex partner and no symptoms of the disease. The given subcategory was mentioned as a preventive barrier 
due to the lack of knowledge about the disease since there was no reason to prevent it when the spouse or the partner had no warts. For example, a 22 -year-old married woman stated that "My husband did not have warts. That is, maybe he had it a few years ago and it had been disappeared now. I do not know, maybe he had it and did not tell me anything, maybe she had this virus but he did not know about it".

No exposure to symptoms was similarly considered as a barrier to disease prevention. According to the participants, one could not be informed about the disease because the lesions were invisible. In this line, one of the participants added that "One cannot understand anything from a person's appearance. One cannot figure it out because there is no place to be seen physically" (22 years old, married, bachelor's degree).

\section{Discussion}

In this qualitative study, the experiences of women with HPV in dealing with disease symptoms were discussed for the first time in the related literature. Given the experiences of women with HPV, psychological responses and physical experiences of the disease could affect their referrals for treatments and prevention of HPV complications including its progression to cervical cancer (Table 2).

\section{Psychological Experiences}

Experiences from the majority of the participants showed that psychological responses of the disease were in most cases the reason for not referring to healthcare centers for treatment. The HPV was also associated with psychological distress (25). The psychological burden of the occurrence of HPV was further due to the status of women's relationships, their social norms, as well as their cultural forms with their own adverse social and psychological consequences $(26,27)$.

Moreover, most participants were extremely worried about the transmission of the disease to the fetus and such a concern was the cause of continuing treatments. However, worrying about the incurability of the disease led to disappointment in individuals and made them neglect following disease treatments. In a study, the participants were worried about fertility (28). Some participants also considered cancer as a "deadly disease" and believed that they could even have had cancer as they talked about it (29). In another view study, cancer was chronic and incurable, and screening for the diagnosis was only fatal and could not be prevented, thus screening was not beneficial (30).

The vast majority of the participants were afraid of confronting the disease, which had resulted from the fears of cancer and death, as well as the recurrence and worsening of the disease. Additionally, some participants described this fear as a reason to seek treatments and prevent cancer. In another study, women with HPV had a fear of cancer (20). The misconceptions about the fatalities of cancer and the fear of diagnosis and treatment had prevented the screening of cervical cancer $(29,31)$.

Furthermore, unbelievable acceptance was reported by more than half of the study participants and they complained about their HPV infection or that of their husbands and believed that they had been ill due to bad luck. This mischief and belief in bad luck was a factor in caring for the health, as well as a barrier to prevention. In another investigation on women, HPV infection was attributed to misery and mishap (20).

A number of participants experienced unpleasant emotions such as depression and emotional failure due to the discontinuation of therapy as the barriers to HPV prevention. Nervousness was also reported as a feeling among the majority of the participants that prevented the decision for treatment. In one study, women felt shocked, disturbed, anxious, and stressed (32) and some women felt angry (33). In the current study, shame and embarrassment, as well as the feelings of guilt and regret were experienced by most participants and prevented them from referring to healthcare centers for treatment. In two qualitative studies in this domain, embarrassment and shame were common responses of most participants and the shame of genital warts was a barrier to screening $(30,34)$. Like the present study, a number of participants also felt guilty and worried about the transmission of infection in another investigation. Some interviewed women were similarly worried about infecting someone else (32). Based on the findings of another study, women with HPV experienced the negative emotions of shame and stigma (19).

The reactions of the affected person with the disease were expressed by a large number of participants. These individuals had conflicts with their spouses because they considered their husband as the cause of being infected with HPV. In a qualitative study, some women were angered by the fact that their sex partner had infected them with a serious and carcinogenic virus (35). In the present study, half of the participants did not take the virus seriously and sought no treatments. According to the findings of another study, some participants denied their illness and seek no diagnosis and treatment (21). Several participants also hid the virus from their spouse because they were worried about their husbands' suspicions. This concealment was considered as a barrier to the prevention of disease complications. As mentioned in the same studies, the stress of disease disclosure was the most difficult aspect of managing HPV infection. Further, participants were concerned about the disclosure of the illness to their spouses because they thought their husband might doubt their loyalty $(28,35)$.

Additionally, many participants cited the reactions by people, family, and husbands as the barriers to prevent the disease. In this subcategory, a range of taboos for the disease in the community, negative attitudes, and misbehaviors, as well as family interference were considered as the 
barriers to seeking treatments. Many participants further complained about the negative attitudes of individuals around them, and they considered it as a reason to hide the disease. According to one study, patients' fear of talking about the illness to their families was one of the barriers to receive support and treatment (20). Women were also very anxious about talking to family members, and some of them decided not to let anyone know because they were concerned about the immorality stigmatized to themselves (36).

In this study, a number of participants complained about their husband's secrecy, disapproval, and disregard and cited them as barriers to prevent HPV. In a qualitative study in Taiwan, a number of women believed that no man on earth was completely loyal and reliable. Particularly in cases where the husband and wife had recently been in conflicts, positive results of HPV tests led to questions about the husband's trust and loyalty (26). Based on the reports of two other studies, sex partner was considered as one of the barriers to referrals to healthcare and prevention centers $(31,37)$. Nevertheless, one of the participants spoke about her husband's loyalty and acceptance. Furthermore, the findings of a qualitative study revealed that some husbands of women with HPV were worried about their health and sought to obtain information on disease treatment while encouraging their spouses to continue their treatments (36).

\section{Physical Experiences}

The majority of participants highlighted the physical experiences of the disease as the facilitators of its prevention. Clinical symptoms such as warts, burning and itching, vaginal discharge, and symptom recurrence also led them to refer to healthcare centers. Itching, burning, and vaginal infection were similarly among the symptoms that prompted people to visit the doctor quickly. Moreover, most participants referred to healthcare centers as they observed warts while the long incubation period of the virus and the hidden symptoms of the disease were barriers to prevention since there was no reason to prevent the disease while there were no warts in their spouse or sex partner. Women with HPV often followed medical advice (29) in the face of disease symptoms that did not respond to in-home treatments. In one study, HPV infection was significantly associated with vaginal inflammation and cervical cancer (38). HPV infection could sometimes occur with other vaginal infections. The clinical manifestations of HPV infection included genital and anal warts (39). In general, the results of this study shed light on the importance of understanding the risk of developing HPV in the face of disease symptoms. It should be noted that the non-generalizability of qualitative research results was one of the limitations of this study although the discovery of participants' thoughts and beliefs was considered as one of the strengths in this domain.

\section{Conclusions}

This study attempted to explain the experiences of women with HPV in the face of disease symptoms. Women with HPV could also understand and experience physical and psychological problems, which were first described along with its dimensions in Iran via this qualitative study. Participants' experiences in dealing with HPV symptoms were also divided into two categories. The first group included psychological responses with the sub-categories of concern, fear, panic, in addition to unbelievable acceptance, unpleasant feelings, an individual's response to the disease, and reactions by people, family, and husband in the face of the disease. In addition, physical experiences of the disease with the subcategories of clinical symptoms and a long incubation period of the virus were regarded as the other group. The psychological responses and physical experiences of women with HPV could be effective in preventing HPV complications and its progress to cervical cancer. Further, differences in the provision of healthcare services, as well as sociocultural issues could lead to specific HPV prevention models. Considering the serious complications of the lack of follow-up and treatments, as well as the prevention of HPV infection, while providing a specific prevention program, it was recommended to provide prevention counseling in community health centers, along with advising and guiding patients in specialist therapy clinics.

\section{Conflict of Interests}

Authors declare that they have no conflict of interests.

\section{Ethical Issues}

This article was obtained from a Ph.D. dissertation in Reproductive Health fulfilled at Shahid Beheshti University of Medical Sciences under the ethical code of IR.SBMU.PHNM.1395.459.

\section{Financial Support}

This study received no financial support.

\section{Acknowledgments}

The authors express their gratitude to all participants for their contributions to this study..

\section{References}

1. Centers for Disease Control and Prevention (CDC). Genital HPV Infection - Fact Sheet. CDC; 2017. https://www.cdc. gov/std/hpv/hpv-Fs-July-2017.pdf.

2. World Health Organization (WHO). Sexually Transmitted Infections (STIs). WHO; 2013. http://www.who.int/ reproductivehealth/publications/rtis/rhr13_02/en/.

3. ICO/IARC HPV Information Centre. Iran: Human Papillomavirus and Related Cancers, Fact Sheet. 2017. http://www.hpvcentre.net/statistics/reports/IRN_FS.pdf.

4. Clifford GM, Rana RK, Franceschi S, Smith JS, Gough G, Pimenta JM. Human papillomavirus genotype distribution in low-grade cervical lesions: comparison by geographic 
region and with cervical cancer. Cancer Epidemiol Biomarkers Prev. 2005;14(5):1157-1164. doi:10.1158/10559965.epi-04-0812

5. Fakhraei F, Haghshenas MR. Human Papillomaviruses and Cancer. Journal of Mazandaran University of Medical Sciences. 2013;23(98):458-480. [Persian].

6. Dunne EF, Markowitz LE. Genital human papillomavirus infection. Clin Infect Dis. 2006;43(5):624-629. doi: $10.1086 / 505982$

7. Sabeena S, Bhat PV, Kamath V, Aswathyraj S, Arunkumar G. Knowledge, attitude and practice concerning human papilloma virus infection and its health effects among rural women, Karnataka, South India. Asian Pac J Cancer Prev. 2015;16(12):5053-5058. doi:10.7314/apjcp.2015.16.12.5053

8. Zandi K, Eghbali SS, Hamkar R, et al. Prevalence of various human papillomavirus (HPV) genotypes among women who subjected to routine Pap smear test in Bushehr city (south west of Iran) 2008-2009. Virol J. 2010;7:65. doi:10.1186/1743-422x-7-65

9. Bhatla N, Lal N, Bao YP, Ng T, Qiao YL. A meta-analysis of human papillomavirus type-distribution in women from South Asia: implications for vaccination. Vaccine. 2008;26(23):2811-2817. doi:10.1016/j.vaccine.2008.03.047

10. Houlihan CF, Larke NL, Watson-Jones D, et al. Human papillomavirus infection and increased risk of HIV acquisition. A systematic review and metaanalysis. AIDS. 2012;26(17):2211-2222. doi:10.1097/ QAD.0b013e328358d 908

11. Wiley DJ, Douglas J, Beutner K, et al. External genital warts: diagnosis, treatment, and prevention. Clin Infect Dis. 2002;35(Suppl 2):S210-224. doi:10.1086/342109

12. Garland SM, Steben M, Sings HL, et al. Natural history of genital warts: analysis of the placebo arm of 2 randomized phase III trials of a quadrivalent human papillomavirus (types 6,11, 16, and 18) vaccine. J Infect Dis. 2009;199(6):805-814. doi:10.1086/597071

13. Banura C, Sandin S, van Doorn LJ, et al. Type-specific incidence, clearance and predictors of cervical human papillomavirus infections (HPV) among young women: a prospective study in Uganda. Infect Agent Cancer. 2010;5:7. doi:10.1186/1750-9378-5-7

14. Centers for Disease Control and Prevention (CDC). HPVAssociated Cancers Rates by Race and Ethnicity. CDC; 2014. http://www.cdc.gov/cancer/hpv/statistics/race.html.

15. Lowy DR, Solomon D, Hildesheim A, Schiller JT, Schiffman M. Human papillomavirus infection and the primary and secondary prevention of cervical cancer. Cancer. 2008;113(7 Suppl):1980-1993. doi:10.1002/cncr.23704

16. Murray M. Progress in preventing cervical cancer: updated evidence on vaccination and screening. Outlook. 2010;27(2):1-12.

17. Dominiak-Felden G, Cohet C, Atrux-Tallau S, Gilet H, Tristram A, Fiander A. Impact of human papillomavirusrelated genital diseases on quality of life and psychosocial wellbeing: results of an observational, health-related quality of life study in the UK. BMC Public Health. 2013;13:1065. doi:10.1186/1471-2458-13-1065

18. Daley EM, Perrin KM, McDermott RJ, et al. The psychosocial burden of HPV: a mixed-method study of knowledge, attitudes and behaviors among
HPV+ women. J Health Psychol. 2010;15(2):279-290. doi:10.1177/1359105309351249

19. Sheaves C. Evaluating Changes in Knowledge, Beliefs, and Behaviors Associated with HPV Following an Educational Intervention among Women. Morgantown, West Virginia: Nursing School; 2015.

20. O'Connor M, Costello L, Murphy J, et al. 'I don't care whether it's HPV or ABC, I just want to know if I have cancer.' Factors influencing women's emotional responses to undergoing human papillomavirus testing in routine management in cervical screening: a qualitative study. BJOG. 2014;121(11):1421-1429. doi:10.1111/14710528.12741

21. Reich M, Licitra L, Vermorken JB, et al. Best practice guidelines in the psychosocial management of HPV-related head and neck cancer: recommendations from the European Head and Neck Cancer Society's Make Sense Campaign. Ann Oncol. 2016;27(10):1848-1854. doi:10.1093/annonc/ mdw272

22. Gentles SJ, Charles C, Nicholas DB, Ploeg J, McKibbon KA. Reviewing the research methods literature: principles and strategies illustrated by a systematic overview of sampling in qualitative research. Syst Rev. 2016;5(1):172. doi:10.1186/ s13643-016-0343-0

23. Tesch R. Qualitative Research: Analysis Types and Software Tools. London: Routledge; 2013.

24. Grunbaum JA, Kann L, Kinchen S, et al. Youth risk behavior surveillance--United States, 2003. MMWR Surveill Summ. 2004;53(2):1-96.

25. Chelimo C, Wouldes TA, Cameron LD, Elwood JM. Risk factors for and prevention of human papillomaviruses (HPV), genital warts and cervical cancer. J Infect. 2013;66(3):207-217. doi:10.1016/j.jinf.2012.10.024

26. Qi SZ, Wang SM, Shi JF, et al. Human papillomavirusrelated psychosocial impact of patients with genital warts in China: a hospital-based cross-sectional study. BMC Public Health. 2014;14:739. doi:10.1186/1471-2458-14-739

27. Wang KL, Jeng CJ, Yang YC, et al. The psychological impact of illness among women experiencing human papillomavirus-related illness or screening interventions. J Psychosom Obstet Gynaecol. 2010;31(1):16-23. doi: $10.3109 / 01674820903564440$

28. Lin H, Jeng CJ, Wang LR. Psychological responses of women infected with cervical human papillomavirus: a qualitative study in Taiwan. Taiwan J Obstet Gynecol. 2011;50(2):154158. doi:10.1016/j.tjog.2011.01.035

29. Vahabi M, Lofters A. Muslim immigrant women's views on cervical cancer screening and HPV self-sampling in Ontario, Canada. BMC Public Health. 2016;16(1):868. doi:10.1186/s12889-016-3564-1

30. Fort VK, Makin MS, Siegler AJ, Ault K, Rochat R. Barriers to cervical cancer screening in Mulanje, Malawi: a qualitative study. Patient Prefer Adherence. 2011;5:125-131. doi:10.2147/ppa.s17317

31. Ebu NI, Mupepi SC, Siakwa MP, Sampselle CM. Knowledge, practice, and barriers toward cervical cancer screening in Elmina, Southern Ghana. Int J Womens Health. 2015;7:3139. doi:10.2147/ijwh.s71797

32. Campaner AB, Vespa Junior N, Giraldo PC, Leal Passos MR. Adverse Psychosexual Impact Related to the Treatment of 
Genital Warts and Cervical Intraepithelial Neoplasia. J Sex Transm Dis. 2013;2013:264093. doi:10.1155/2013/264093

33. McRae J, Martin C, O'Leary J, Sharp L. "If you can't treat HPV, why test for it?" Women's attitudes to the changing face of cervical cancer prevention: a focus group study. BMC Womens Health. 2014;14:64. doi:10.1186/1472-687414-64

34. Salad J, Verdonk P, de Boer F, Abma TA. "A Somali girl is Muslim and does not have premarital sex. Is vaccination really necessary?" a qualitative study into the perceptions of Somali women in the Netherlands about the prevention of cervical cancer. Int J Equity Health. 2015;14:68. doi:10.1186/ s12939-015-0198-3

35. McCaffery KJ, Irwig L, Turner R, et al. Psychosocial outcomes of three triage methods for the management of borderline abnormal cervical smears: an open randomised trial. BMJ. 2010;340:b4491. doi:10.1136/bmj.b4491
36. Jeng CJ, Lin H, Wang LR. The effect of HPV infection on a couple's relationship: a qualitative study in Taiwan. Taiwan J Obstet Gynecol. 2010;49(4):407-412. doi:10.1016/s10284559(10)60090-3

37. Tu YC, Wang HH. An exploration of human papillomavirusrelated cervical cancer prevention experiences among college women: a descriptive qualitative approach. J Clin Nurs. 2013;22(23-24):3300-3309. doi:10.1111/jocn.12051

38. Manga MM, Fowotade A, Abdullahi YM, et al. Epidemiological patterns of cervical human papillomavirus infection among women presenting for cervical cancer screening in North-Eastern Nigeria. Infect Agent Cancer. 2015;10:39. doi:10.1186/s13027-015-0035-8

39. Juckett G, Hartman-Adams H. Human papillomavirus: clinical manifestations and prevention. Am Fam Physician. 2010;82(10):1209-1213.

(c) 2020 The Author (s); This is an open-access article distributed under the terms of the Creative Commons Attribution License (http://creativecommons.org/licenses/by/4.0), which permits unrestricted use, distribution, and reproduction in any medium, provided the original work is properly cited. 